\title{
Determinants of Neurocognitive Impairment in HIV in a Cohort of Patients on Antiretroviral Therapy Followed in Bangui (Central African Republic)
}

\author{
Mbelesso Pascal1', Tekpa Gaspard'2, Ndouongou-Kouna Philomène ${ }^{3}$, \\ Yangatimbi Emmanuel1, Amakade-Woyengba Phrygie Avilah4, Honisse Hortense ${ }^{5}$ \\ ${ }^{1}$ Neurology Department, Hôpital de l'Amitié de Bangui, Bangui, Central African Republic \\ ${ }^{2}$ Department of Infectious and Tropical Diseases, Hôpital de l'Amitié de Bangui, Bangui, \\ Central African Republic \\ ${ }^{3}$ Université des Sciences de la Santé, Libreville, Gabon \\ ${ }^{4}$ Faculté des Sciences de la Santé, Université de Bangui, Bangui, Central African Republic \\ ${ }^{5}$ Hôpital de Jour, Centre National Hospitalier Universitaire de Bangui, Bangui, Central African Republic \\ Email: pmbelesso@yahoo.com
}

Received 19 December 2015; accepted 7 March 2016; published 10 March 2016

Copyright (C) 2016 by authors and Scientific Research Publishing Inc.

This work is licensed under the Creative Commons Attribution International License (CC BY).

http://creativecommons.org/licenses/by/4.0/

c) (i) Open Access

\begin{abstract}
Infection with HIV is one of the deadliest epidemics of our time and its type is widespread in the Central African Republic. It is frequently accompanied by neurological complications. Objective: To contribute to a better understanding of neurocognitive disorders in patients living with HIV (PLHIV) in Bangui, and to identify associated factors using the International HIV Dementia Scale (IHDS) as a screening tool. We conducted a descriptive and analytical cross-sectional study from 1 December 2014 to 30 January 2015, in a cohort of patients seen on one of the supported sites in Bangui. A total of 400 patients were received in follow-up visit during the study period of which 244 met the inclusion criteria. The prevalence of neurocognitive disorders was $25 \%$, $95 \%$ CI [19.70 - 30.92]. The mean age of subjects was $42.77 \pm 9.58$ with extremes ranging from $24-64$ years. The sex ratio (F/M) was 4.5 in. The average score for different tests was $10.93 \pm 1.13$ with extremes of 7 and 12. The disorder was more about the gestural sequence. Determinants of neurocognitive disorders in the cohort were older age and lower educational level $(p<0.05)$. It is useful to conduct further studies to confirm these results by combining a battery of neuropsychological tests to recommend this test for all the support sites of PLHIV in the country.
\end{abstract}

\section{Keywords}

HIV, Neurocognitive Disorders, Determinants, Central African Republic 


\section{Introduction}

Infection with human immunodeficiency virus (HIV) is one of the deadliest epidemics of our time. According to the Antiretroviral treatment (ART) 2013 UNAIDS report, 35.5 million people were living with HIV worldwide in 2012 including 2.3 million new infections, a reduction of incidence of 33\% over 2011. AIDS mortality records also down from 2.3 million in 2005 to 1,600,000 in 2012 [1]. It is a disease whose transmission is done either through sex, either through blood or from mother to child during pregnancy at the time of childbirth or during breastfeeding. High risk factors of its transmission are: sex homo/heterosexual unprotected, the use of contaminated equipment, blood exposure accidents. The diagnostic criteria in Central Africa based on two serological tests that are the Determine HIV 1 \& 2 and HIV 1 \& 2 Unigold. Both tests should be positive simultaneously to confirm the diagnosis of HIV/AIDS.

In Central African Republic, HIV is generalized type with a prevalence of 4.9\% [2]. This has motivated the introduction of multi therapy 1996, causing the infection is better controlled but not always eliminated.

Having helped to restore a satisfactory immune function and control viral replication by ensuring that the viral load is undetectable. Thus the HIV infection has become a chronic disease. These treatments have also helped to reduce the opportunistic infections that can occur during infection.

HIV infection is frequently accompanied by neurologic complications [3]. It is shown from the beginning of the epidemic that HIV is present early in the central nervous system (CNS) [4]. Despite more effective ARV treatment, the virus can persist in the brain causing symptoms of neurological and psychological diseases. In addition, some ARV are toxic to the CNS. These neurological have neurocognitive disorders (NCD), which are highly prevalent among PLHIV. Before the era of highly active antiretroviral therapy (HAART), the incidence of HIV-associated dementia (DAV) is high. With the advent of ARTs, the prevalence of DAV dropped NCD phenotype has changed and is diagnosed more moderate neurocognitive disorders [5]-[7]. The first symptoms of dementia complex associated with HIV are mainly attention disorders and concentration associated with memory disorders in which patients are more or less aware. These symptoms are all the more precocious than the cultural level of patients which is very low, with reference to the hypothesis of brain reserve applied to Alzheimer's disease. Psychomotor retardation sets in parallel are often more obvious to the entourage for the patient himself. Sometimes, a manic state may inaugurate an HIV encephalopathy. At this early stage, the sensitivity, specificity and positive predictive value of a detailed neuropsychological evaluation proved to detect HIV encephalopathy are valued at respectively $67 \%, 92 \%$ and $95 \%$ [8]. After a few weeks or months, occur apathy, emotional indifference, loss of motivation with total disinterest and ambulatory difficulties characterize the status phase. At the advanced stage, the dementia is severe confining the patient in silence, with fecal and urinary incontinence and paraplegia related often associated myelopathy. There is no disturbance of consciousness until an advanced stage of dementia [9]. An international committee recently proposes a consensual revision of the diagnostic criteria for neurocognitive disorders associated with HIV [10]. The new classification of neurocognitive disorders has three levels of increasing severity: asymptomatic neuropsychological deficit, mild cognitive impairment and dementia associated with HIV [10].

These disorders have a negative impact not only on the achievements of the most demanding activities of daily living (housework, money calculation, driving etc.) in PLVIH associated with a loss of autonomy [11] but also adherence to treatment and social and professional integration of the latter [12]. Hence, the importance of their early detection to optimize their management and prevent progression to dementia as proven. That is why we invested in this work whose general objective was to contribute to a better understanding of neurocognitive disorders in people with HIV on one of the supported sites in Bangui, and to identify associated factors.

\section{Methodology}

We conducted a descriptive and analytical cross-sectional study from 1 December 2014 to 30 January 2015, in a cohort of patients seen on one of the supported sites in Bangui. The subjects were elderly PHIV 18+ included, treated with ARTs for at least one month with an updated medical record containing a CD4 count at initiation of ART and another in the last month study, the date of ART initiation. The study protocol was approved by the Scientific Committee responsible for the validation of study protocols and results which ethics committee office in Central Africa. All subjects gave informed consent and included signed an informed consent form.

Did not make the study, admitted PLHIV hospitalization, those with active disease of the CNS (meningitis, encephalopathy...) or intercurrent infection, or those whose health does not allow to undergo an interview. The 
test used for screening NCD was that of the International HIV Dementia Scale (IHDS) which compote:

- The timed tapping finger which measures the driving speed (executive functions), during which the patient must type with the index and middle finger of non-dominant hand as quickly as possible on the table by five seconds;

- The sequence of Luria of repeating as many times as possible the next move: point/palm/slice by hand, with the non-dominant hand in 10 seconds and that tests programming ability and psychomotor speed;

- A repeat of four Dubois words given in the beginning of test, which tests the episodic memory.

Data collection was made during consultations followed with a single survey form, including socio-demographic, clinical (clinical stage of HIV infection (WHO), biological variables (rates current Nadir CD4 and CD4), antiretroviral regimens and duration, results IHDS test.

Data were analyzed using Epi data 7 software. Chi-square test and/or the Fischer were used to compare the proportions with a degree of significance set at $5 \%$.

\section{Results}

A total of 400 patients were received in follow-up visit during the study period of which 244 met the inclusion criteria.

Of 224 patients enrolled, sixty had a disruption in neurocognitive tests matched hundred eighty three witnesses. The distribution by age and gender of the subjects included in the study is presented in Table 1 . The prevalence of neurocognitive disorders was $25 \%$, 95\% CI [19.70 - 30.92]. The average age of the subjects was $42.77 \pm$ TNC 9.58 with extremes ranging from 24 - 64 years. The sex ratio (F/M) was 4.5 in NCD. The average score for different tests was $10.93 \pm 1.13$ with extremes of 7 and 12 . The disorder was more about the gestural sequence (psychomotor speed). Patients in couples accounted for $47.54 \%$, while fourth was single; almost half of the patients had a secondary study (42.6\%). The average duration of ART was $29.06 \pm 21.02$ months. In $75 \%$ of cases, the patients had treatment duration of less than 39.70 months and the median duration was 28.76 months with extremes of 8 and 128.86 months; the average CD4 at initiation of treatment was $175 \pm 126$ $\mathrm{CD} 4 / \mathrm{mm}^{3}$ and was correlated with the non-performance of the subjects in IHDS. The Determinants of neurocognitive disorders in the cohort are shown in Table 2. The high age and low education were the factors associated with neurocognitive disorders $(p<0.05)$.

\section{Discussion}

HIV infection in Central African Republic is generalized type with a national prevalence of 4.9\% [13]. It mainly affects young individuals between 20 and 40 years, as evidenced by the very young age of the patients in our study whose median age was 38 years. This has been done in other African countries [14] [15] and Latin America [16]. This is explained partly by risky sexual behavior reported in the country [14]. Furthermore, the prevalence of HIV infection was twice as high among women (6.3\%) than men (3\%) in our [14], which we found in our cohort patients.

Table 1. Distribution by age and gender of the subjects included in the study.

\begin{tabular}{|c|c|c|c|c|c|c|}
\hline \multirow{3}{*}{$\begin{array}{c}\text { Age } \\
\text { (years) }\end{array}$} & \multicolumn{6}{|c|}{ Sex } \\
\hline & \multicolumn{2}{|c|}{ Male } & \multicolumn{2}{|c|}{ Female } & \multicolumn{2}{|c|}{ Total } \\
\hline & $\mathrm{N}$ & $\%$ & $\mathrm{~N}$ & $\%$ & $\mathrm{~N}$ & $\%$ \\
\hline $15-24$ & 0 & 0 & 9 & 100 & 9 & 3.69 \\
\hline $25-34$ & 8 & 10.81 & 66 & 89.19 & 74 & 30.33 \\
\hline $35-44$ & 25 & 25.77 & 72 & 74.23 & 97 & 39.75 \\
\hline $45-54$ & 16 & 34.04 & 51 & 65.96 & 47 & 19.26 \\
\hline$\geq 55$ & 7 & 41.18 & 10 & 58.82 & 17 & 6.97 \\
\hline Total & 56 & 22.95 & 188 & 77.05 & 244 & 100 \\
\hline
\end{tabular}


Table 2. Factors determining neurocognitive disorders in the cohort.

\begin{tabular}{|c|c|c|c|c|c|c|}
\hline Determinants Factors & & NCD Presents $(\mathrm{N}=61)$ & & NCD absents ( $\mathrm{N}=183)$ & & $p$ \\
\hline \multirow[t]{3}{*}{ Sex } & & & & & & 0.29 \\
\hline & Male & 11 & 19.64 & 45 & 80.36 & \\
\hline & Female & 50 & 26.6 & 136 & & \\
\hline \multirow[t]{3}{*}{ Age (years) } & & & & & & 0.0006 \\
\hline & $>40$ & 24 & 18.45 & 109 & 81.95 & \\
\hline & $\geq 40$ & 37 & 33.33 & 74 & 66.67 & \\
\hline \multirow[t]{3}{*}{ Marital status } & & & & & & 0.76 \\
\hline & Couple & 69 & 24.17 & 91 & 75.83 & \\
\hline & Single & 32 & 28.91 & 92 & 74.49 & \\
\hline \multirow[t]{3}{*}{ Social status } & & & & & & 0.32 \\
\hline & Unemployed & 41 & 27.15 & 110 & 72.85 & \\
\hline & Workers & 20 & 21.5 & 73 & 78.5 & \\
\hline \multirow[t]{3}{*}{ Instruction level } & & & & & & 0.018 \\
\hline & Unschooled/Primary & 31 & 33.33 & 62 & 66.67 & \\
\hline & College/University & 30 & 19.87 & 121 & 80.13 & \\
\hline \multirow[t]{3}{*}{ Clinal stage WHO } & & & & & & 0.93 \\
\hline & 1 et 2 & 22 & 25.29 & 65 & 74.71 & \\
\hline & 3 et 4 & 39 & 24.84 & 118 & 75.16 & \\
\hline \multirow[t]{3}{*}{ ART at CD4 initiative $\left(/ \mathrm{mm}^{3}\right)$} & & & & & & 0.053 \\
\hline & $<200$ & 36 & 30 & 84 & 70 & \\
\hline & $\geq 200$ & 20 & 18.87 & 86 & 81.13 & \\
\hline \multirow[t]{3}{*}{ Current CD4 (/mm³) } & & & & & & 0.13 \\
\hline & $<200$ & 14 & 38.9 & 22 & 61.1 & \\
\hline & $\geq 200$ & 33 & 25.9 & 94 & 74.1 & \\
\hline \multirow[t]{3}{*}{ Therapeutic protocol } & & & & & & 0.25 \\
\hline & With EFZ & 28 & 28.87 & 69 & 71.13 & \\
\hline & Without EFZ & 33 & 22.45 & 114 & 77.55 & \\
\hline \multirow[t]{3}{*}{ ART duration (in months) } & & & & & & 0.63 \\
\hline & $<24$ & 24 & 23.76 & 77 & 76.24 & \\
\hline & $\geq 24$ & 36 & 26.47 & 100 & 73.53 & \\
\hline
\end{tabular}

NCD: Neurocognitives disorders; N: Number; ART: Antiretroviral treatment; EFZ: Efavirenz.

The concept of neurocognitive disorders associated with HIV was early highlighted then categorized among AIDS symptoms [17] [18]. Thus several batteries of tests (test clock, 5 words Dubois etc.) have been proposed for screening of dementia in PLHIV [19] including the International HIV Dementia Scale-related or International HIV Dementia Scale [20]. The IHDS is a modification of the scale of dementia related to HIV or HIV Dementia Scale (HDS) developed by Power et al. [21]. It has recently been adapted by Sacktor et al. [22]. It is a tool whose sensitivity and specificity validated allow for screening of dementia among HIV positive populations. 
This tool is easy to use does not require the direct involvement of healthcare professionals; less expensive because it does not require sophisticated instrument other than a watch with a second hand; finally IHDS is language independent and culture [21], thus it is transcultural. It helps identify patients at risk for neurocognitive disorders without the need for sophisticated neuropsychological tests. The specificity and sensitivity of the IHDS for the detection of dementia with a score less than or equal to 10 are $55 \%$ and $80 \%$ respectively in the Ugandan cohort [22] [23] and 57\% and $80 \%$ in the cohort US [22]. In Brazil [24], the specificity is 55\% and specificity of $80 \%$; in South Africa $45 \%$ and $79 \%$ [25]. These data have confirmed our IHDS to use as a screening tool.

\subsection{Prevalence}

In Central African Republic, the prevalence of neurocognitive disorders in the general population especially that of dementia was determined at $8.1 \%$ in the elderly [26]. But we do not have data on the prevalence of neurocognitive impairment in HIV in the country. The IHSD allowed us to find a prevalence of $25 \%$ among PLHIV. This percentage is in the range of the value of work done elsewhere that have reported rates ranging from $20 \%-50 \%$ [5] [27]. Studies using the IHDS helped to bring a similar rate of $21 \%$ in Cameroon. As against our finding is slightly lower than the 38\% prevalence found in Botswana and that of 33\% in Guyana [15] [27] [28]. This demonstrates the extent of this phenomenon in HIV patients, especially since HIV has neurotropism with early dissemination to the central nervous system, the source of various complications [29]. Studies using another screening tool (basic test battery) also had results comparable to ours in Aquitaine [30] or 24\%, while in the united states (38\%) and Uganda (31\%) rates well higher have been reported [11] [20]. But it is the IHDS is advised. Furthermore IHDS compared the MMSE (Mini Mental State Examination) detect much on the NCD HIV field [31]. Note that HIV-related dementia has an annual incidence of 7\% after development of AIDS and ultimately affects $20 \%$ of people infected with HIV. If the incidence and severity of neurocognitive disorders have decreased, their prevalence continues to increase because of the elongation of the survival of patients and insufficient effectiveness of antiretroviral neurotoxicity induced by viral replication [5] [32]. Accurate and early diagnosis of HIV dementia can lead to treatment decisions and optimized management [21].

\subsection{The Performance of Patients to Different Tests}

The average total score for the study population was 11. This average is identical to that found in Guyana [28]. Among PLHIV with NCD, the average score was 9 and in the US cohort (9.3) as well as in the Ugandan cohort when it was 9.9 [11]. Our finding is similar to that reported in Nigeria (8.36) by Oshinaike Olajumoke et al. [31], in Cameroon (9.4) by Njamnshi et al. [27]. This argues for the universality of the use of IHDS.

\subsection{The Performance for Each Neuropsychological Test}

Concerning the under parts of the test, the sequence of Luria (concerning the gestural sequence) was difficult to achieve by our patients with NCD with a median score of 2. This score is similar to that reported in Guyana [28]. Moreover, this finding corroborates data reported in the literature [25] [27] [33]. This highlights the predominant involvement of the programming capacity by the patients in our study.

\subsection{Determinants}

\subsubsection{Sex}

Of the 61 patients with NCD, women were more numerous with a sex ratio (F/M) 4.5. But sex did not have a statistically significant effect $(p=0.29)$ on the occurrence of disorders. This result goes in the same direction as that of the US and Ugandan cohort [22]. This can be a simple observation, because even for Alzheimer's disease in the general population, it has been reported that femininity is often associated with increased risk of this disease [34].

\subsubsection{Ages}

Among patients with the NCD, the median age was 42 years. Patients older than 40 years were more likely to have these disorders $(33.4 \%)$ for all subjects $(p=0.0060)$. Our findings show that the higher the patient is elderly it is more likely to develop neurocognitive disorders. This fact was reported by African literature [27] [35]. In 
our case, age over 40 years was associated with a risk of having a positive test. Similarly converging results have allowed us to confirm this correlation, especially in the Aquitaine cohort where age over 46 years was associated with a higher risk of having a positive test. At Bicêtre, the prevalence of NCD was high (50\%) with a median age of 67 years [30]. A paper presented by Cross et al. also raised the link between age and the NCD [36]. For against Nakku et al. in their work on NCD risk factors in the population of Uganda reported that advanced age and neurocognitive disorders association was not demonstrated [37]. This phenomenon could be explained by certain stressful situations that seniors would face and which we have escaped. Because we have not administered batteries of neuropsychological tests to the subjects of the study, our objective is to test the IHDS for the rapid determination of the NCD in the cohort followed for PLHIV on the site.

\subsubsection{Education Level}

Out of school sick or who left school at the primary level were more likely to develop the NCD $(p=0.018)$. This finding reinforces the data from the study in India which had noted that the low level of education was significantly associated with the performance of The IHDS [38]. This result goes in the same direction as that presented by Bonnave in Guyana [39]. Cross et al. 2013 in an article also showed a low level of education was associated with the occurrence of a NCD [36]. These findings corroborate the studies already conducted in the general population on dementia [40]-[42]. Thus, the low educational level reduces, in addition to the neuronal degeneration induced by the virus, neuronal plasticity phenomenon that would protect against dementia [43] [44].

\subsubsection{The CD4 Count at Treatment Initiation}

We found that $30 \%$ of patients with NCD had fewer than $200 \mathrm{CD} 4 / \mathrm{mm}^{3}$ before treatment and that this rate did not affect the performance of subjects with IHDS and therefore was not associated with the NCD. This finding is contrary to that reported by Gray indicating that the frequency of increased TNC when the CD4 count was lower than 200/ $\mathrm{mm}^{3}$ [45], as well Njamnshi et al. have shown that a low CD4 count was predictive of the NCD [27].

Furthermore, the current CD4 count at diagnosis had no impact on the performance of the NCD test we used. This finding has been reported in Botswana [15] and corroborates the facts reported that the CD4 count as well as other biomarkers such as plasma viral load and the cerebrospinal fluid are not correlated or are not predictive of neurocognitive disorders [46]. The finding that the current CD4 count is not associated with the performance on IHDS was predictable since most subjects received HAART.

\subsubsection{The Time on Treatment}

Like all degenerative diseases, it is difficult for society and the family to take preventive measures, apart from accompanying the patient for his regular use of antiretroviral therapy.

We found that $28.9 \%$ of patients with NCD were under treatment containing the efavirenz for over 24 months. But they were no more affected by the unrest because it would be led to think otherwise holding the account of the toxicity of efavirenz on the brain [47]. The duration of ART does not intervene in the appearance of the NCD. This confirms the data reported in the literature that in the event of infringement of the cognitive functions of HIV, the standard treatment is based on a combination antiretroviral therapy involving at least three molecules, whose aim is to block viral replication in the periphery and in the central nervous system. Such a regimen has demonstrated its ability to improve, at least partially, cognitive deficit, although the assessment criteria vary from one study to another [48]. Several recent studies have shown that the preferential use of neuroactive called antiretrovirals, that is to say have a better level of penetration and efficiency in the cerebral compartment provides an additional benefit virological [49], cognitive [50] [51] and survival [52]. However, there are other controversies that taking highly active therapy for several years threatens to constitute all factors that can worsen or even be the cause of NCD, what we have found. This is in line with this assertion that prolonged exposure of the brain to TAR originally NCD was not shown.

\section{Conclusion}

Our data show that the IHDS is a rapid screening tool that can be used in Central Africa to identify people at risk of developing HIV-associated dementia or cognitive impairment associated with HIV. However, it cannot replace the neuropsychological tests adapted for the accurate diagnosis of dementia associated with HIV. But it is 
useful to point to the diagnosis of NCD associated with HIV among at-risk patients and appears to be suitable for limited-resource countries such as Central African Republic. This first study in the country has successfully used IHDS worth pursuing by combining with a battery of neuropsychological tests. If the results are conclusive, the IHDS can be recommended for all supported sites PLHIV for screening NCD associated with HIV.

\section{References}

[1] Onusida (2013) Rapport sur l'épidémie mondiale du sida.

[2] Fonds des Nations Unis pour la Population., UNFPA/Bangui et ICF International (2012) Prévalence de l'infection à VIH et facteurs associés en République Centrafricaine en 2010. Calverton Maryland.

[3] Levy, R.M., Bredesen, D.E. and Roserblum, M. (1988) Opportunistic Central Nervous System Pathology in Patients with AIDS. Ann Neural, 23, 7-12. http://dx.doi.org/10.1002/ana.410230706

[4] Davis, L.E., Hjelle, B.L., Miller, V.E., Palmer, D.L., Llewellyn, A.L. and Merlin, T.L. (1992) Early Viral Brain Invasion in Iatrogenic Human Immunodeficiency Virus Infection. Neurology, 42, 1736-1739. http://dx.doi.org/10.1212/WNL.42.9.1736

[5] Robertson, K.R., Smurzynski, M., Parsons, T.D., Wu, K., Bosch, R.J., Wu, J., et al. (2007) The Prevalence and Incidence of Neurocognitive Impairment in the HAART Era .AIDS, 21, 1915-1921. http://dx.doi.org/10.1097/QAD.0b013e32828e4e27

[6] McArthur, J.C. (2004) Attenuated Central Nervous System Infection in Advanced HIV/AIDS with Combination Antiretroviral Therapy. Archives of Neurology, 61, 1687-1696. http://dx.doi.org/10.1001/archneur.61.11.1687

[7] Heaton, R.K., Clifford, D.B., Franklin Jr., D.R., Woods, S.P., Ake, C. and Vaida, F., et al. (2010) HIV-Associated Neurocognitive Disorders Persist in the Era of Potent Antiretroviral Therapy. Neurology, 75, 2052-2094. http://dx.doi.org/10.1212/WNL.0b013e318200d727

[8] Cherner, M., Masliah, E., Ellis, R.J., Marcotte, T.D., Moore, D.J., Grant, I., et al. (2002) Neurocognitive Dysfunction Predicts Post Mortem Findings in HIV Encephalopathy. Neurology, 59, 1563-1567. http://dx.doi.org/10.1212/01.WNL.0000034175.11956.79

[9] Nath, A. and Berger, J. (2004) HIV Dementia. CNS Infection, 6, 139-151. http://dx.doi.org/10.1007/s11940-004-0023-6

[10] Antinori, A., Arendt, G., Becker, J.T., Brew, B.J., Byrd, D.A., Cherner, M., et al. (2007) Updated Research Nosology for HIV-Associated Neurocognitive Disorders. Neurology, 69, 1789-1799. http://dx.doi.org/10.1212/01.WNL.0000287431.88658.8b

[11] Robertson, K.R., Nakasujja, N., Wong, M., Musisi, S., Katabira, E., Parsons, T.D., et al. (2007) Pattern of Neuropsychological Performance among HIV Positive Patients in Uganda. BMC Neurology, 7, 8. http://dx.doi.org/10.1186/1471-2377-7-8

[12] Hinkin, C.H., Hardy, D.J., Mason, K.I., Castellon, S.A., Durvasula, R.S., et al. (2004) Medication Adherence in HIVInfected Adults: Effect of Patient Age, Cognitive Status, and Substance Abuse. AIDS, 18, 19-25. http://dx.doi.org/10.1097/00002030-200401001-00004

[13] Fonds des Nations Unis pour la population (2010) Prévalence de l’infection à VIH et facteurs associés en RCA. Mics-4 RCA.

[14] Organisation Mondiale de la Santé (2011) Le VIH en Afrique subsaharienne, rapport de situation. http://www.who.int/about/licensing/copyright_from/en/index.html

[15] Lawler, K., Mosepele, M., Ratcliffe, S., Seloilwe, E., Steele, K., Nthobatsang, R., et al. (2010) Neurocognitive Impairment among HIV-Positive Individuals in Botswana: A Pilot Study. Journal of the International AIDS Society, 13, 15-23. http://dx.doi.org/10.1186/1758-2652-13-15

[16] Lopardo, G., Bissio, E., Iannella, M.D., Crespo, A.D., Garone, D. and Cassetti, L. (2009) Good Neurocognitive Performance Measured by the International HIV Dementia Scale in Early HIV-1 Infection. Journal of Acquired Immune Deficiency Syndromes, 52, 488-492. http://dx.doi.org/10.1097/QAI.0b013e3181b06348

[17] Alperovitch, A., Schwarzinger, M., Dufouil, C., Dartigues, J.F., Ritchie, K. and Tzourio, C. (2004) Vers une prévention de la démence ? Revue Neurologique, 160, 256-260. http://dx.doi.org/10.1016/S0035-3787(04)70900-5

[18] Moulignier, A. (2006) Atteintes du système nerveux central et infection par le VIH-1. Revue Neurologique, 162, $22-42$. http://dx.doi.org/10.1016/S0035-3787(06)74980-3

[19] Organisation Mondiale de la Santé (2008) VIH/Sida et santé mentale. OMS Conseil exécutif.

[20] Poissonet, A. (2008) Les tests cognitifs: Eléments de diagnostic et de suivi: Pourquoi et comment traiter un patient âgé dément ? Réseau de Santé Paris Nord, Paris. 
[21] Power, C., Selnes, O.A., Grim, J.A. and McArthur, J.C. (1995) HIV Dementia Scale: A Rapid Screening Test. Journal of Acquired Immune Deficiency Syndrome and Human Retrovirology, 8, 273-278. http://dx.doi.org/10.1097/00042560-199503010-00008

[22] Sacktor, N.C., Wong, M., Nakasujja, N., Skolasky, R.L., Selnes, O.A., Seggane, M., et al. (2005) The International HIV Dementia Scale: A New Rapid Screening Test for HIV Dementia. AIDS, 19, 1367-1374.

[23] Bottiggi, K.A., Chang, J.J., Schmitt, F.A., Avison, M.J., Mootoor, Y., Nath, A., et al. (2007) The HIV Dementia Scale: Predictive Power in Mild Dementia and HAART. Journal of the Neurological Sciences, 260, 11-15. http://dx.doi.org/10.1016/j.jns.2006.03.023

[24] Rodrigues, R.A., Oliviera, R.L., Grinsztejn, B. and Silva, M.T.T. (2013) Validity of the International HIV Dementia Scale in Brazil. Arquivos de Neuro-Psiquiatria, 71, 376-378. http://dx.doi.org/10.1590/0004-282x20130042

[25] Joska, J.A., Westgarth-Taylor, J., Hoare, J., Thomas, K.G.F., Paul, R., Myer, L., et al. (2011) Validity of the International HIV Dementia Scale in South Africa. AIDS Patient Care and STDS, 25, 95-101. http://dx.doi.org/10.1089/apc.2010.0292

[26] Mbelesso, P., Tabo, A., Guerchet, M., Mouanga, A.M., Bandzouzi, B., Houinato, D., et al. (2012) Epidémiologie des démences chez les personnes âgées dans le troisième arrondissement de la ville de Bangui (République Centrafricaine). Bulletin de la société de pathologie exotique, 105, 388-395. http://dx.doi.org/10.1007/s13149-012-0247-8

[27] Njamnshi, A.K., Djientcheu, V.P., Fonsah, J.Y., Yepnjio, F.N., Njamnshi, D.M. and Muna, W.F. (2008) The International HIV Dementia Scale Is a Useful Screening Tool for HIV-Associated Dementia/Cognitive Impairment in HIVInfected Adults in Yaoundé-Cameroon. Journal of Acquired Immune Deficiency Syndromes, 49, 393-397. http://dx.doi.org/10.1097/QAI.0b013e318183a9df

[28] Bonnave, N. (2011) Dépistage par l'international hiv dementia scale des troubles neurocognitifs parmi les patients séropositifs au VIH de l’ouest guyanais. Thèse de doctorat en médecine, Université de Guyane, Cayenne.

[29] Moulignier, A. (2007) Le complexe démentiel associé au VIH: Aspect particuliers chez les sujets âgés. Psychologie \& NeuroPsychiatrie du vieillissement, 5, 193-207.

[30] Bonnet, F.A.H. and Bruyand, M. (2009) High Prevalence of Mild Neurocognitive Disorders in HIV-Infected Patients. ANRS CO3 Aquitaine Cohort 2009, 474.

[31] Oshinaike Olajumoke, O., Akinbami, A., kinsegun, A., Ojo Oluwadamilola, O., Ojini, I.F., Okubadejo, U.N., et al. (2012) Comparison of the Minimental State Examination Scale and the International HIV Dementia Scale in Assessing Cognitive Function in Nigerian HIV Patients on Antiretroviral Therapy. AIDS Research and Treatment, 2012, 1-6. http://dx.doi.org/10.1155/2012/581531

[32] Brew, B.J. (2004) Evidence of a Change in AIDS Dementia Complex in the Era of Highly Active Antiretroviral Therapy and the Possibility of New Forms of AIDS Dementia Complex. AIDS, 18, S75-S78. http://dx.doi.org/10.1097/00002030-200401001-00011

[33] Golden, C.J., Sweet, J., Hammeke, T., Purisch, A., Graber, B. and Osmon, D. (1980) Factor Analysis of Luria-Nebraska Neuropsychological Battery. I. Motor, Rhythm, and Tactile Scales. International Journal of Neuroscience, 11, 91-99. http://dx.doi.org/10.3109/00207458009150331

[34] Qiu, C., De Ronchi, D. and Fratiglioni, L. (2007) The Epidemiology of the Dementias: An Update. Current Opinion in Psychiatry, 20, 380-385. http://dx.doi.org/10.1097/YCO.0b013e32816ebc7b

[35] Sacktor, N., Nakasujja, N., Okonkwo, O., Skolasky, R.L., Robertson, K., Musisi, S., et al. (2013) Longitudinal Neuropsychological Test Performance among HIV Seropositive Individuals in Uganda. Journal of NeuroVirology, 19, 4856. http://dx.doi.org/10.1007/s13365-012-0139-5

[36] Cross, S., Önen, N., Gase, A., Overton, E.T. and Ances, B.M. (2013) Identifying Risk Factors for HIV-Associated Neurocognitive Disorders Using the International HIV Dementia Scale. Journal of NeuroImmune Pharmacology, 8, 1114-1122. http://dx.doi.org/10.1007/s11481-013-9505-1

[37] Nakku, J., Kinyanda, E. and Hoskins, S. (2013) Prevalence and Factors Associated with Probable HIV Dementia in an African Population: A Cross-Sectional Study of an HIV/AIDS Clinic Population. BMC Psychiatry, 13, 126-132. http://dx.doi.org/10.1186/1471-244X-13-126

[38] Waldrop-Valverde, D., Nehra, R., Sharma, S., Malik, A., Jones, D., Kumar, A.M., et al. (2010) Education Effects on the International HIV Dementia Scale. Journal of NeuroVirology, 16, 264-267. http://dx.doi.org/10.3109/13550284.2010.497808

[39] Mukherjee, J., Farmer, P., Nityizonkiza, D., Mccorkle, L., Vanderwarker, C. and Teixeira, P. (2003) Tackling HIV in Resource Poor Countries. BMJ, 327, 1104-1106. http://dx.doi.org/10.1136/bmj.327.7423.1104

[40] Herrera Jr., E., Caramelli, P., Silveira, A.S. and Nitrini, R. (2002) Epidemiologic Survey of Dementia in a CommunityDwelling Brazilian Population. Alzheimer Disease \& Associated Disorders, 16, 103-108. http://dx.doi.org/10.1097/00002093-200204000-00007 
[41] Prencipe, M., Ferretti, C., Casini, A.R., et al. (1997) Stroke, Disability, and Dementia: Results of a Population Survey. Stroke, 28, 531-536. http://dx.doi.org/10.1161/01.STR.28.3.531

[42] Ravaglia, G., Forti, P., Maioli, F., Sacchetti, L., et al. (2002) Education, Occupation, and Prevalence of Dementia: Findings from the Conselice Study. Dementia and Geriatric Cognitive Disorders, 14, 90-100. http://dx.doi.org/10.1159/000064930

[43] Stern, Y. (2006) Cognitive Reserve and Alzheimer Disease. Alzheimer Disease \& Associated Disorders, 20, $112-117$. http://dx.doi.org/10.1097/01.wad.0000213815.20177.19

[44] Katzman, R. (1993) Education and the Prevalence of Dementia and Alzheimer's Disease. Neurology, 43, 13-20. http://dx.doi.org/10.1212/wnl.43.1_part_1.13

[45] Gray, F. (1998) Dementia and Human Immunodeficiency Virus Infection. Journal of Neurology, 154, 2591-2598.

[46] Tozzi, V., Balestra, P., Bellagamba, R., Corpolongo, A., Salvatori, M.F., Visco-Comandini, U., et al. (2007) Persistence of Neuropsychological Deficits Despite Long-Term Highly Active Antiretroviral Therapy in Patients with HIVRelated Neurocognitive Impairment: Prevalence and Risk Factors. Journal of Acquired Immune Deficiency Syndromes, 45, 174-182. http://dx.doi.org/10.1097/QAI.0b013e318042e1ee

[47] Ford, N., Shubber, Z., Pozniak, A., Victoria, M., Doherty, M., Kirby, C., et al. (2015) Comparative Safety and Neuropsychiatric Adverse Events Associated with Efavirenz Use in First-Line Antiretroviral Therapy: A Systematic Review and Meta-Analysis of Randomized Trials. Journal of Acquired Immune Deficiency Syndromes, 69, 422-429.

[48] Grant, I., Sacktor, N. and McArthur, J. (2005) HIV Neurocognitive Disorders. In: Gendelman, H.E., Grant, I., Everall, I.P., et al., Eds., The Neurology of AIDS, Oxford University Press, New York, 357-373.

[49] Letendre, S., Marquie-Beck, J., Capparelli, E., Best, B., Clifford, D., Collier, A.C., et al. (2008) Validation of the CNS Penetration-Effectiveness Rank for Quantifying Antiretroviral Penetration into the Central Nervous System. Archives of Neurology, 65, 65-70. http://dx.doi.org/10.1001/archneurol.2007.31

[50] Letendre, S.L., McCutchan, J.A., Childers, M.E., et al. (2004) Enhancing Antiretroviral Therapy for Human Immunodeficiency Virus Cognitive Disorders. Archives of Neurology, 56, 416-423. http://dx.doi.org/10.1002/ana.20198

[51] Tozzi, V., Balestra, B., Salvatori, M.F., et al. (2008) Changes in Cognition during HAART: Comparison of Two Different Scoring Systems to Measure Antiretroviral Drug Efficacy on HIV-Dementia. Proceedings of the 15th Conference on Retroviruses and Opportunistic Infections, Boston, 3-6 February 2008.

[52] Lanoy, E., Bentata, M., Guiguet, M., et al. (2007) Improvement of Survival after a Neurological AIDS Defining Event over Time. Proceedings of the 11th European AIDS Conference, Madrid, 24-27 October 2007.

\section{Abbreviations}

AIDS: Acquis immunodeficiency syndrome

ART: Antiretroviral treatment

CNS: Central nervous system

DAV: HIV-associated dementia

HAART: Highly active antiretroviral therapy

HDS: HIV dementia scale

HIV: Human immunodeficiency virus

IHDS: International HIV Dementia Scale

NCD: Neurocognitive disorders

PLHIV: Patients living with human immunodeficiency virus

US: United State 